\title{
La revolución industrial 4.0 necesita formar líderes para innovar, más allá de la publicidad educativa; 0 , Algunos ejemplos para recurrir a la formación filosófica en la formación de líderes (I).
}

The Industrial Revolution 4.0 needs to train leaders to innovate, beyond educational advertising; or, Some examples to resort to philosophical formation in the formation of leaders (I).

Esta obra está bajo una Licencia Creative Commons Atribución 4.0 Internacional. DOI: $10.32870 /$ sincronia.axxiii.n75.4a19

\author{
Eduardo Quintana Salazar \\ Departamento de Filosofía \\ Universidad de Guadalajara \\ mutakallimum@yahoo.com.ar \\ (MÉXICO)
}

Recibido: $13 / 08 / 2018$

Revisado: $17 / 10 / 2018$

Aprobado: 01/11/2018

\section{RESUMEN}

Tomaremos como base algunos de los estudios, sus datos generales, de algunas revistas de negocios en las que exponen las cualidades que poseen. De ahí nos iremos a los recuerdos del pasado, llamaremos recuerdos del futuro, como algunos astroarqueólogos lo usaban para referirse al pasado. Ese pasado lo situaremos en la filosofía de la Grecia clásica, en tiempos de Jenofonte y Sócrates pasando por una vía de innovación propuesta en el México del siglo XVII para transportarla al México actual. Por ende, la presente exposición pretende llevar al estudio de la filosofía para fortalecer y 
humanizar el estudio de la administración y la formación de líderes que tanto necesita México en la revolución 4.0.

Palabras clave: Administración. Agricultura. Liderazgo. Universidades. Filosofía.

\begin{abstract}
We will take as a basis some of the studies, their general data, of some business magazines in which they expose the qualities that they possess. From there we will go to the memories of the past, we will call memories of the future, as some astroarchaeologists used it to refer to the past. That past we will place in the philosophy of classical Greece, in the times of Xenophon and Socrates going through a route of innovation proposed in Mexico in the seventeenth century to transport it to present-day Mexico. Therefore, this exhibition aims to lead the study of philosophy to strengthen and humanize the study of the administration and training of leaders that Mexico so badly needs in the 4.0 revolution.
\end{abstract}

Keywords: Administration. Agricultura. Leaderships. Universities. Philosophy.

\title{
Desarrollo
}

Como introducción a la presente reflexión tomo una noticia aparecida el 23 de septiembre de este año (Milenio, 2018) en el que se menciona que México producto de sus tratados de libre comercio 16 aparecen en la nota- por 650 millones de dólares, con un potencial humano de 1,592 millones de personas y el $62.40 \%$ del PIB del mundo, sin contar los acuerdos que tiene con el Acuerdo Integral y Progresista de Asociación Transpacifíco -antes llamado Acuerdo TransPacífico, antes de la renuncia de Estados Unidos-, más China, la India, Rusia y algunos países árabes, con lo cual sube muchísimo más en los tres rubros. Así que deberíamos ver a México más allá de su territorio, para pensarlo como: el "México-Global". De ahí que se entienda la necesidad de formar líderes que sean capaces de influir más allá del mismo territorio nacional, y que no debe de estar sujeto a unas cuantas 
universidades -principalmente privadas- pero no se va a lograr mucho si no hay reconciliación entre las grandes masas excluidas del desarrollo, que voluntariamente muchas de ellas dejaron de laborar en diversas empresas por los bajos salarios y las malas condiciones laborales, más allá de la autoimagen que generan para ganar credibilidad social. Para conocer un poco más de cerca la noción que se tiene de liderazgo, consultamos varias listas que aparecen en varias revistas, así como comentarios que se hacen en ellas y en notas periodísticas sobre la noción de líder. Para posteriormente proponer que en la formación de los mismos se recurra a la formación filosófica a fin de evitar el solipsismo que suele afectar, principalmente a los grandes empresarios, o esa es la imagen que transmiten por su cerrazón o falta de flexibilidad para vincularse con las grandes masas de mexicanos. Esto se ha de pensarse dentro de la llamada revolución industrial 4,0 y la sociedad del conocimiento.

En cuanto al liderazgo de empresas mexicanas, actualmente unas han decidido invertir en África, mercado sin aprovechar por los nacionales, según Sheila A. Sánchez, Bimbo, Cemex, SuKarne, Gruma y KidZania han apostado en explorar ese continente desde Marruecos, Argelia, Egipto, Liberia, Costa de Marfil, Ghana, República del Congo, Angola, y Sudáfrica, entre otros. México, en este continente, ha crecido en más de un $86 \%$, ante el crecimiento de la clase media en esos lugares, a decir de Carlos Eduardo Sánchez, responsable de la Unidad de promoción de Negocios Globales de México (Expansión, 15 de abril de 2018).

Empezamos con los datos que nos ofrece la revista "Líderes de México", que desde 2001 publica su listado de los 300 líderes del país, en trece rubros: ciencia, cultura, deportes, empresarios, espectáculos, líderes de opinión, medios, organizaciones civiles, poder ejecutivo, poder judicial, poder legislativo, políticos, profesionales. Analicé la edición (Líderes de México, Julio 2017) ${ }^{1}$, que contiene 300 líderes, de estos: 234 tienen licenciatura, 148 estudiaron en universidad privada y 86 en pública; de 66 no se sabe o no se registró en ella. De los 234; 81 tienen maestría, 46 con doctorado y 16 con alguna especialidad. Los estudios de licenciatura son variados, los hay en

\footnotetext{
${ }^{1}$ Por las fechas de entrega del presente artículo no se presentan los datos del 2018.
} 
historia, física, en educación media, médico-cirujano, estudios culturales, arquitectura, filosofía, sistemas computacionales, en ciencias políticas, artes plásticas, sociología, teología, arquitectura y planeación, artes, finanzas, música, contabilidad y finanzas, derecho y ciencias sociales, mercadotecnia, ciencias políticas y sociales, ciencias y técnicas de la información, pedagogía, relaciones industriales, economía, derecho, ciencias de la computación, administración de empresas, administración de negocios, y contaduría pública. Entre las ingenierías destacan: agronomía zootecnista, geofísica, mecánica y eléctrica, agrónoma, mecánica, eléctrica en comunicaciones, en electricidad, química y civil.

Entre las maestrías destacan los estudios: en administración, derecho, historia, políticas públicas, artes visuales, ciencias en desarrollo, finanzas, ingeniería, administración pública, finanzas, ingeniería en estadística, sociología, economía, administración de empresas inmobiliarias y constructivas, administración de empresas. Ciencias médicas, alta dirección, humanidades, derecho constitucional y amparo en impuestos, relaciones internacionales, estudios latinoamericanos, filosofía política, sistemas de información, seguridad nacional, asuntos internacionales y finanzas, derecho penal, filosofía y administración naval. En los estudios de doctorado destacan: en derecho, administración, historia, economía y administración, ciencias de la gestión, ciencias sociales, economía, derecho público, literatura comparadas, estudios profundizados en sociología, gobierno y políticas públicas, ciencias sociales y humanidades.

No aparece ninguna especialidad en ciencias del espacio, cultura de la paz, educación ni estudios sobre la felicidad, psicología, psiquiatría, epistemología, entre otras no mencionadas. Lo que nos hace pensar que no han registrado líderes con dichos perfiles o no son considerados importantes, son no usuales, no tomadas en cuenta o ignoradas por los supuestos líderes actuales de México, ni empresarios, políticos, religiosos o intelectuales estudian sobre ellas para transformar el país. Al menos hubo algunos -muy escasos- formado en las humanidades, y una mínima minoría con formación filosófica. 
En otra revista, ahora: “Petróleo y energía” (noviembre-diciembre, 2016) presentan a los 100 líderes de la industria del petróleo; de ellos, 46 son egresados de universidad pública y 41 de la privada, ambos son 87, del resto (13) no aparecen datos. Entre ambos se juntas 83 maestrías y 30 doctorados. A nivel licenciatura destacan las profesiones: abogado, ingeniería mecánica y eléctrica, ingeniería industrial, derecho, gestión política y administración pública, ingeniería geofísica, economía, ingeniería civil, ingeniería química, administración, relaciones internacionales, ingeniería mecánica, ingeniería geológica, ingeniería petrolera, contabilidad, matemáticas, ciencias computacionales, ingeniería química metalúrgica, ciencias químicas, ingeniería en energía, ingeniería en sistemas, física, y electrónica y comunicación. Algunas de las especialidades son: estudios en alta dirección, economía política internacional, administración pública, economía política, en evaluación, programa ejecutivo del sector de energía, planeación estratégica en finanzas y administración, derecho comercial y financiero, filosofía social, administración y evaluación, en finanzas, energía renovable, y, derecho administrativo.

Entre las maestrías estudiadas destacan: en marketing y gestión comercial, gestión retroambiental, ciencias, administración pública en desarrollo internacional, en administración, en ciencias tecnológicas del petróleo, en ciencias tecnológicas, del petróleo y petroquímica, administración con especialidad en finanzas, economía e historia, ingeniería química, ingeniería en exploración petrolera, economía de la energía, economía internacional y desarrollo, en dirección y gestión pública local, gerencia en procesos, regulación económica, en dirección de negocios, en ingeniería y gestión ambiental, derecho marítimo, ingeniería petrolera, ingeniería de proyectos, ingeniería de yacimientos, economía política, derecho y diplomacia, derecho internacional, interpretación de la reforma energética y leyes secundarias, servicio a clientes, mercadotecnia, ejecutiva en administración, alta dirección de empresas, metalurgia, cinética de polimerización, ingeniería petrolera, sistemas electrónicos en potencia, investigación en operaciones, recursos energéticos, gestión pública aplicada, y, geofísica aplicada. 
Entre los estudios de doctorado destacan: en gestión pública, finanzas, administración de empresas, en filosofía con especialidad en finanzas, ingeniería en flujos electrodinámicos, ciencias políticas, economía, filosofía, ingeniería eléctrica, fisicoquímica, administración pública, geofísica aplicada, ingeniería química, sociología, economía del petróleo, ingeniería petrolera, ingeniería energética, derecho de empresa, y, administración y dirección de empresas. Tampoco aparece ninguna especialidad en ciencias del espacio, cultura de la paz, educación ni estudios sobre la felicidad, psicología, psiquiatría, pero al menos hubo algunos -muy escasos- formados en la filosofía. Por ello siguen sin mejorar las condiciones laborales de millones de trabajadores -y sus familias- ni socio-cultural-educativas-de salud esos mexicanos ante la indiferencia de la clase dorada de los partidos políticos y grandes empresarios egoístas. En nuestro caso mexicano, sostenemos lo anterior, apoyados en las reflexiones de Iker Belausteguigoitia (1974), en su momento director de Manufacturas Lock, S. A., ya que, para él, el hombre era el fundamento básico de la empresa. Sostenía que no había muerto "en nuestro interior ese hombre liberal egoísta, que socialmente es un cadáver" (Aranguren, Amescua y Basagoiti, 1974, p. 23). Afirmaba que ese burgués agónico estaba sentenciado a morir por la realidad económica e identificaba el error que se debía evitar en el empresariado mexicano: “El error consiste en pretender que el hombre pueda lograr éxitos económicos estables sirviéndose de los demás, no en comunidad y solidaridad con ellos" (Aranguren et al., 1974, p. 27).

Además, considera que la empresa debería de dar un sentido de vida y una estructura familiar, se lamentaba en su tiempo que no lo estaban haciendo de manera conveniente pues trasplantaban a un simple campesino, desconociendo -y muchas veces despreciando- su sabiduría natural y particular que heredó, para pasar a ser un simple peón de fábrica con todas las complicaciones de convivencia, habitación, transporte en su nueva vida en la ciudad. Afirma: “Hemos mejorado quizá su economía material, pero le hemos destrozado su plataforma de principios básicos, porque no le hemos ayudado a trasplantar los que tenía a su nueva situación de vida" (Aranguren et al., 1974, p. 29). Las crisis económicas recurrentes que ha vivido México desde 
hace casi cincuenta años, destrozaron familias heredadas y su sabiduría aprendida en su afán de sobrevivir, los padres de familia se fueron a trabajar, los hijos a las guarderías, a ser cuidados por familiares, por los hermanos mayores, solos o en las calles, se provocan varias generaciones de ninis. Hoy en día, no han de olvidar, y si poner en práctica, las nuevas generaciones de empresarios, administradores y líderes mexicanos, la petición que hace Belausteguigoitia:

He querido llamar la atención de lo que, por la precipitación de los acontecimientos, se nos escapa: el reflexionar que somos parte de esa gran transformación necesaria del ser hombre y lo dejamos en el olvido, siendo que es, queramos o no, causa, motivo y fin principal de la empresa y de la economía. (Aranguren et al., 1974, p. 30)

Como parte de esta transformación de ser hombre que no se ha de olvidar en la empresa y en la economía ayuda a introducir las palabras de Francisco A. Casasús (1974), empresario de su tiempo, ya que pedía en ese mismo orden de ideas, "humanizar nuestras empresas si queremos que la economía, la sociedad y el Estado lleguen a ser un ámbito favorable para el hombre" (Aranguren et al., 1974, p.40). Que no debe de ser un monopolio de empresario sino un patrimonio común a todos los hombres, dice este empresario y afirma: "la humanización de las empresas no exige: respeto al trabajador y respeto a sus organizaciones" (Aranguren et al., 1974, p. 42). Y adelantándose a la idea del nuevo presidente de México afirmaba, contrario a empresarios temerosos, que: "Una economía por el hombre no es aquella que reserva el poder total de decisión a una minoría. Una economía para el hombre no puede ser orientada a llenar las necesidades de un grupo privilegiado" (Aranguren et al., 1974, p. 42). Y hace suyas las palabras de su antiguo maestro de la Escuela Nacional Preparatoria, el filósofo Antonio Caso, lleno de esperanzas:

Tu siglo es egoísta y perverso. Ama, sin embargo, a los hombres de tu siglo que parecen no saber ya amar, que sólo obran por hambre y por codicia. El que hace un acto bueno sabe que existe lo sobrenatural, el que no lo hace no lo sabrá nunca. Todas las filosofías de los hombres de ciencia no valen nada ante la acción desinteresada de un hombre de bien. (Aranguren et al., 1974, p. 44) 
Fernando Aranguren, también empresario del tercer cuarto del siglo pasado, reconocía que había trabajos que realizaban las personas, duros, aburridos, opresores, que mataban el espíritu y generaban discordias, que impide que las personas de autorrealicen, están ahí por necesidad, por lo que reconoce que hay empresas que deshumanizan el trabajo del hombre. Que fue equivocada la tendencia de la dirección de empresas que se centró únicamente en su finalidad económica "y se olvidó de los trabajadores que vivían en la miseria" (Aranguren et al, 1974, p. 47). De ahí que entiende la molestia que sienten no sólo los sindicatos sino las masas trabajadoras, por lo que se necesita una reconciliación entre ambas partes, en México, por lo que pedía que era momento de ir más allá del bienestar para llegar al bienser. En el primero sigue el trabajador prisionero de dicho afán dice Aranguren, pero si se quiere cambiar dicha situación de ellos hay que empezar a humanizar el trabajo. Por eso creo que en la naciente revolución industrial 4.0 y en la 4T (cuarta transformación de México) necesitamos conciliar a los estudios de las humanidades y el mundo laboral-empresarial. NO más ataques a las humanidades con el pretexto de privilegiar los estudios técnicos, y deben ser los filósofos ${ }^{2}$ los primeros en retomar las propuestas de los empresarios humanistas mexicanos que se reunieron para exponer el pensamiento empresarial mexicano que dieron lugar a un libro en 1974 que tiene hoy más que nunca mucho que decir. Varios de ellos leían y conocían de la filosofía, la consideraban importante en su formación personal; los formadores de líderes deberían volver a ella de manera definitiva, sobre todo por lo que expondremos más adelante.

Aranguren retomaba las palabras del papa Juan XXIII -hoy nombrado santo- que el sistema productivo no pusiera en peligro la dignidad humana por lo que también esta a favor de concebir la empresa, como una "empresa humanista", por lo que cualquier empresa debería de contribuir al

\footnotetext{
${ }^{2}$ A su vez, los filósofos deberán de cambiar mucho, abandonar sus prejuicios contra las empresas y empresarios; deberán cambiar sus planes de estudio para incorporar materias y perfiles de egreso afines a los nuevos retos, salir del aula para que los estudiantes puedan realizar su servicio social y prácticas profesionales en alguna organización, incluida la empresas; la nueva generación de filósofos no temerá desarrollar habilidades tecno-prácticas -como pedía Kant-; deberán hacerse a la idea de que la administración es filosofía aplicada; entre otros cambios.
} 
bienser y que la administración no debe de responder al desarrollo social y económico sino que lo ha de crear, así que cree que no hay países subdesarrollados sino países subadministrados, por lo que afirma: "La calidad de vida dependerá cada vez más de la calidad de administración de la sociedad" (Aranguren et al., 1974, p. 51). Por lo que no se puede reducir, como ahora se hace en algunas empresas, la presencia de filósofos, en los comité de ética, la presencia del filósofo debe ir más allá apoyando con su formación en epistemología, lógica, fundamentos de las matemáticas, filosofía del lenguaje, principios fundamentales de la ciencia, historia de la ciencia, antropología filosófica, filosofía de la mente, y estética -entre otras- a los consejos empresariales o de negocios, así como directores o directivos de centros de investigación e innovación -que cada vez crecerán más dentro de las empresas del país por sus formación que equilibra los fundamentos de la ciencia, saber epistemológico, lógico y humanístico-, así como el apoyo de las humanidades en general, si se quiere desarrollar el bienser en sus trabajadores. Estoy convencido de que las empresas que incorporen a este tipo de filósofo -no cualquiera tiene esa formación- podrá tener ventaja competitiva dentro de la naciente revolución industrial 4.0 y dentro del ambiente de la sociedad del conocimiento.

El bienser, para Aranguren, dentro de la empresa, primero es necesario que la dirección sea consciente de entender y aplicar la noción de enriquecimiento del trabajo, la participación, la capacitación, el estilo de mando y todo aquello que contribuya a que las personas que laboran sean mejores en todo el sentido de la palabra, así fomentará el bienser del trabajador; no más explotación como se hace en muchas empresas ${ }^{3}$ en México, donde trabajan sin descansar, no los quieren que paren a descansar y los castigan si intercambian palabras entre sí, sólo lo pueden hacer

\footnotetext{
${ }^{3}$ Por los medio de comunicación y redes sociales quieren dar una buena imagen, pero son los mismos trabajadores los que desmientes ese espejismo. Para el empresario José María Basagoiti (1974) que desde el momento en que se ve a sus subordinados desde el puesto de la gerencia, ahí empieza el abuso de autoridad, como privilegio o soberbia por lo que dentro de la empresa se generan falsas ideas de libertad y de igualdad: "El hombre en la empresa quiere ser libre y, por libre, comprometido, vinculado en todas las características de la empresa: en las de carácter económico en las de carácter social, en las de carácter intelectual. El hombre desea estar informado para poder estar motivado. Desea aportar de sí lo más, aportarse a sí mismo para recibir para sí lo más, para hacerse a sí mismo para recibir para sí lo más, para hacerse más a sí mismo". (Aranguren et al., 1974, p. 121)
} 
en su tiempo de descanso, de las que echan pestes -esas personas- en el transporte público, en casas, escuelas y con amigos. Esos empresarios o direcciones de empresas ya deberán aprender a delegar responsabilidades a sus trabajadores, y aceptar las decisiones tomadas por ellos, como se verá más adelante cuando hablemos de filosofía griega clásica.

Retomando a Aranguren, éste pedía que no siguiera ocurriendo dicho trabajo opresor ambiente laboral opresor-, por lo que la actitud de los directivos de las empresas debería cambiar y aceptar la participación individual y colectiva de sus trabajadores, garantizando la libertad y responsabilidad de los mismos, que no se olvide que el trabajador contribuye en la creación de la riqueza por lo que deberían premiarlo liberando su actividad y responsabilidad para volverse más creativo, hoy se dice, innovador. En fin a de procurar:

el bienser del trabajador cuando se le capacita mejor en su trabajo, cuando se le localiza donde puede hacer uso de sus aptitudes personales y su vocación, cuando se le da la oportunidad de saber en forma más completa sobre lo que hace y darle oportunidad de autocapacitarse para ser promovido. (Aranguren et al., 1974, p. 53)

Aranguren pedía se confiara mucho en la juventud y que el empresariado debería de apoyarlos -no sólo a sus hijos- sino a las masas mexicanas, por medio de capacitación laboral -hoy regresa el sistema de aprendices- así como en colaborar con estrechamente con el gobierno mexicano y las universidades -no sólo las privadas- centro de capacitación y otras instituciones pues ha de entender que la empresa es gestora no solo de bienestar sino también de bienser. A su vez, el empresario Alejandro Garza pedía que en México se abandone la fuerte hostilidad hacia los hombres de negocios, que ya se le vea como los grandes -gandallas- explotadores de los trabajadores y de la naturaleza; así como tampoco se les vea sólo a ellos como empresarios. Pide no olvidar que tan empresario son los grandes como los medianos y chicos -incluidos los changarros familiares-. Que todos estos son responsables del desarrollo de las comunidades, en la medida de sus posibilidades. 
El filósofo Antonio Ibargüengoitia (1995) nos recuerda que el término empresa se debe de entender como el arte de emprender, y que emprender es usar la capacidad humana de tomar decisiones; por lo que desde la más tierna infancia se inician nuestras empresas individuales, y que siempre estamos emprendiendo cosas que afectan nuestra propia existencia; en ese sentido ser filósofo es una manera de emprender, por ende, es una empresa ser filósofo, por ejemplo. A su vez, Alejandro Garza (1974), menciona que todos los hombres por naturaleza somos empresarios, por lo que todos somos responsables del desarrollo de las comunidades mexicanas, por lo que depende de todos que cambie la condición y calidad de vida de todos los mexicanos. Aranguren por ello sostiene que ser empresario hoy debe de ser un reto personal -incluidos los filósofos-, "Un ideal de servicio hacia los demás" (Aranguren et al., 1974, p. 73). Para el destacado hombre de negocios del tercer cuarto del siglo XX, Eloy S. Vallina (1974) mencionaba desde ese tiempo, la necesidad de un nuevo tipo de empresario para México ya que en un mundo de cambios había que cambiar, hay que adaptarse a los cambios constantes todos, sobre todo si por fin queremos abandonar el subdesarrollo.

Otra empresaria de esa época, José María Bassagoiti (1974), reflexionaba sobre la violencia y que es muy vigente a nuestro México sufriente de hoy, que la violencia destruía la justicia "porque destruye su substancia, su materia y su forma" (Aranguren et al., 1974, p. 113). Que no se debería aceptar la violencia porque es un castigo que se impone a sí misma una sociedad desesperada por no encontrar mejores caminos, es un desenlace suicida, define la violencia como "el resultado, expansivo y caótico, de una mala distribución de las esperanzas sociales" (Aranguren et al., 1974, p. 113). A la vez pedía que el empresario no debería de denunciar la violencia por miedo a perder su estatus de privilegio, sino que como miembro de la misma sociedad a de pedir orden, paz y eficiencia para todos, pero no es suficiente por ello para él:

De la suma de las reformas parciales de las empresas es de donde tendrá que surgir la transformación social total. 
El empresario tiene que estar absolutamente convencido de que la reforma de la empresa, mas existencialmente, de la reforma de su empresa, depende la superación de la sociedad. (Aranguren et al., 1974, p. 115)

Pide que el empresario entienda que la empresa nació para servir a la sociedad, la empresa a de acomodarse, adaptarse y ajustarse a lo que la sociedad quiera, ya que, si rechaza a la sociedad, terminará perdiendo. El empresario, como líder, deberá entender y asumir las demandas sociales como suyas, por lo que ya es tiempo de que cambie la mentalidad de los grandes hombres de negocios escuchando a la sociedad, es más, que debe sentirse parte de la misma. Finalmente, considera que la empresa ha de modificar su concepto y estructura "y crear una filosofía que le sirva de guía, exculpación, defensa y apología para satisfacer a los que creen en ella y para tapar la boca a los que la consideran injustificable o irredimible" (Aranguren et al., 1974, pp. 129-130). Para S. Beer (1971) pedía que se reorganizara la enseñanza universitaria de la ciencia administrativa y que el departamento en que debería de colocarse debería de ser en los departamentos de filosofía: "Porque la ciencia administrativa es filosofía aplicada, una filosofía del género que investiga las formas rigurosas de discusión, en vez de debates metafísicos" (p. 517). Para reforzar lo dicho por Beer, recordemos las palabras de Cicerón (2016): “todas las enseñanzas de la filosofía tienen una aplicación en la vida" (Sobre la naturaleza..., I.7). Beer advierte que, sin embargo, muchos filósofos se resistirán a ello, sin embargo, como dijimos más arriba, los filósofos también deben de cambiar, deberá de entender que:

Durante dos mil años, la filosofía ha sido una materia "pura"; muchos filósofos están obstinados orgullosos del desinterés de sus investigaciones respecto de los asuntos cotidianos. Por lo tanto, la ida de una filosofía aplicada que tenga la posibilidad de producir beneficios en la industria y en el comercio, pondrá a muchos científicos al borde de la apoplejía. Pero la apoplejía muy frecuentemente es el precio del progreso". (Beer, 1971, p. 517) 
Les podrá apoplejía a los filósofos ya formados, a los que estemos por formar no han de caer en dicho chantaje, pues concordamos con los dicho más arriba, por parte del empresario Aranguren de que demos mucha confianza a la juventud y que el empresariado debería de apoyarlos, pero no sólo ellos sino otras organizaciones deberán de hacer lo mismo. Pero lo más grato es que las nuevas juventudes, sin importar si son rurales o de ciudad, han decido abrirse las oportunidades por ellos mismos, asumirse como líderes del cambio de la mentalidad y destino de nuestra nación, como el caso de la nueva generación de jóvenes que han decidido ingresar al mundo de la política, identificamos en la revista "Expansión" (15 de abril, 2018), en su ADN político, bajo el título: "El inconformismo activo", de Bianca Carretto, en que presenta a diez jóvenes que pelean por incidir en las decisiones del país, pero rechazan hacerlo por vía de los partidos políticos tradicionales en las pasadas elecciones (2018), ellos son: Pedro Kumamoto, Pablo Montaño, Rodrigo Cornejo, Alberto Valencia, Roberto Castillo, Susana Ochoa, Paola Flores, Adrián Gorocica, Alejandra del Toro, y Carlos Brito. Ellos aspiraban al senado, cámara de diputados, congresos locales, y alcaldía, por Jalisco, Ciudad de México, Yucatán, Nuevo León y Jojutla. Si bien, algunos no llegaron, no han abandonado su intención de cambiar, innovar y transformar con su liderazgo los cambios necesarios para que millones de personas mejores su calidad de vida.

Otro ejemplo de una nueva generación de jóvenes líderes, pero ahora en innovación, lo encontramos en la revista "Manufactura" (abril, 2018) que publica "las 13 promesas de la ingeniería". En esa lista podemos mencionar a Nataly Medina Rodríguez, ingeniera en cibernética electrónica, al usar la tecnología para detectar señales cerebrales en situación de cansancio. Considera que el cansancio mental es común, pero es poco atendido por las organizaciones en administración. También se menciona a Christian Castro Guzmán con su modelo de gestión de la innovación; a Carlos Adolfo Díaz Rodríguez y su desarrollo de redes neuronales aplicadas al cómputo eficiente; a Daniel Arturo Zavala Ortiz y su protocolo de producción y seguimiento en tiempo real para un medicamento antitumoral; a Anahí Velázquez Silva y su factor esencial para un refrigerador; a Daniel Lira y su guante terapéutico; Erik Piedra Martínez y su mejor en la evaluación 
del comportamiento de los componentes por medio de un software de simulación; a Joshua Henderson Villalpando, y su proceso para evitar las fallas biológicas en la producción de detergentes; a Jorge Yajseel Alonso y su sistema de chasis modular de bajo costo; José Martín Vázquez Villa y sus bacterias devoradoras de petróleo para control de derrames; a José González Calderón y su nueva tecnología para usar menos colorante en la pintura y la eliminación de solventes; y, Luis Marcelo Lozano Sánchez y su busca de procesos y materiales para la fabricación de prótesis.

Pero los ejemplos anteriores -datados en dichas revistas- no son suficientes, de ahí que, para Ignacio De la Vega, decano de la Escuela de Negocios del Tec de Monterrey, es necesario luchar contra el déficit de talento; refiere: "Tenemos la responsabilidad de formar a los líderes de nuestras organizaciones. Las instituciones tienen un compromiso con los accionistas, pero debemos lograr que sea compatible con el hecho de que la sociedad avance hacia modelos más justos." (Expansión, 2018, p. 61) Así que hay que buscan formar permanentemente líderes ya que el conocimiento se transforma, por ello: "las competencias empiezan a tener un peso superior." (De la Vega, 2018, p. 61) Pues el conocimiento técnico ya se presupone, ya que, al transformarse las industrias, los modelos de negocios y el conocimiento, hay que generar habilidades que permitan entender el comportamiento del consumidor, por ello se requiere: "la capacidad de liderar equipos de manera diferente al estilo "mando y ordeno"; un liderazgo positivo que refuerza a estos grupos y genera valor." (De la Vega, 2018, p. 61) Considera que la industria de la educación "tenemos una responsabilidad enorme" (De la Vega, 2018, p. 61) por lo escaso de talento, sobre todo, ahora que se buscan emprendedores -proactivos- "con capacidad de diseñar el futuro, no de predecirlo". (De la Vega, 2018, p. 61) Por ello, propone que se requieren

líderes con flexibilidad y resiliencia que puedan tomar decisiones en entornos complejos, así como gestionar toda la abundancia de información que el Big data ofrece. Y luego, gente, que pueda trabajar en equipos cada vez más complejos y, por supuesto, expertos de su área de conocimiento. (De la Vega, 2018, p. 61) 
Otra referencia sobre el liderazgo la encontramos en el periódico "El financiero" del 18 de mayo de 2018, por medio del colaborar invitado, Carlos Ruiz González en su artículo “Liderazgo dinámico", en que presenta al mismo como una nueva manera de referir el liderazgo, como una combinación de liderazgo adaptativo con proactividad, lo que le permite adaptarse con micha mayor facilidad. Menciona que a este liderazgo recurren a la difícil combinación de humildad personal y voluntad profesional para sus logros en sus negocios. Presenta la siguiente ecuación: “Humildad (objetividad con uno mismo) + Férrea determinación (Fortaleza + Voluntad) = Liderazgo dinámico (primero las personas)" (p.11). Otra referencia la encontramos en Ruiz González, profesor del Ipade, que nos recuerda que en enero del presente año (2018), dentro del Foro Económico de Davos -Suiza-, el liderazgo dinámico fue uno de los temas centrales:

La integridad, la inspiración, la inclusión, la autenticidad y la transparencia forman los cinco rasgos principales inmutables del liderazgo. Esos rasgos inmutables no cambian con el tiempo o las tendencias comerciales actuales. Los buenos líderes perfeccionan y refinan estos rasgos como parte de su desarrollo y los incorporan en su ADN". (Ruiz, 2018, p.11)

Este tipo de líder deberá enseñar a sus colaboradores a tratar de crecer respetando a las personas, considerando y respetando su libertad. Para él, el mejor maestro es el ejemplo que practican los líderes auténticos "que muestran su integridad entre lo que dicen y lo que hacen" (Ruiz, 2018, p. 11). Finalmente, pide no se olvide, que: "el liderazgo no es una cualidad innata, es una cualidad desarrollable con esfuerzo y dedicación" (Ruiz, 2018, p. 11).

A pesar de los datos que hemos recogido hasta este momento sobre las nociones y ejemplos que se suelen presentar como liderazgos, como filósofo, deberé advertir, aplicado al caso México, que no basta lo dicho anteriormente ya que, como contra ejemplo, me apoyaré en S. Beer (1977), ya que advierte que cada vez es mayor el peligro "para la libertad humana" (p. 100) por lo que se requieren "nuevos y graves motivos de reflexión" (p. 100). Sostiene que la mayoría de la gente de este planeta esta esclavizada por lo que plantea que la computadora puede utilizarse como un verdadero liberador, por lo que dicho proceso ha de desarrollarse por medio de la educación para 
"restaurar la libre elección del pueblo" (p. 105). Afirma que en su interpretación cibernética: "nuestro cerebro no cuenta con la aptitud de una inconmensurable elasticidad o una infinita capacidad de superación, debido al lastre de tres mil años de cultura precientífica le han dejado en una falsa situación" (p. 107).

Para Beer, nuestro cerebro condiciona nuestras experiencias y por lo tanto nos limita en alguna medida. Así, aquí viene lo grave, ya que nuestro entorno económico, como proceso cultural, nos limita, nos vuelve víctimas inconscientes de dicha variable. Por ello para Beer somos explotados, sobre todo cuando a lo económico se le agrega la ciencia y la tecnología -el mal uso, no la teoría como tal- bajo el falso supuesto de estar al servicio del hombre. Por ello propone que debemos prepararnos para "revisar" dicho modelo disfuncional del actual modelo de civilización que vivimos; a eso agreguemos la llamada sociedad del conocimiento y la misma, llamada, revolución industrial 4.0. Advierte que hoy, más que nunca, está en peligro la "libertad", nuestra libertad, la de cada quien:

es necesario emprender el proyecto de remodelar nuestras instituciones, usando la ciencia con intrepidez en tal empeño. La sociedad, por medio de sus instituciones, tanto públicas como privadas, está haciendo un uso temerario de ella en la actualidad -y no precisamente para diseñar un nuevo sistema, sino para afianzarse a sí misma y reforzar sus aspectos más opresivos (Beer, 1977, p. 153)

Esta opresión se manifiesta en el consumo de masas, advierte Beer, donde se hace mal uso de la ciencia, por ejemplo, en la manipulación por medio de la televisión por medio de la cual se presenta un falso progreso -como lo han hecho los gobernantes en turno en México, por muchos años- por medio del cual se impone "una especie de imperialismo óptico" (Beer, 1977, p. 154). Otro ejemplo para Beer, son los sistemas con que se espia la vid de los ciudadanos -con el pretexto de perseguir terroristas y delincuencia, como en México- y que archivan un dossier de cada uno de nosotros "para cuando sea oportuno privarles de su buena reputación y crédito. A eso se llama opresión" (1977, p. 154). Otra opresión, para Beer, es lo que hacen las empresas multinacionales que explotan 
los recursos limitados del planeta -como las mineras y las empresas que pretenden explotar la reforma petrolera en México- en beneficio de unos pocos que tiene el poder. Por lo que afirma de manera contundente: "Dado que se viene usando la ciencia con fines opresores, al menos empecemos a utilizarla ya al servicio de la libertad" (Beer, 1977, p. 154). Nunca más el uso de la ciencia para fines opresores de la especia humana, sentencia Beer, por lo tanto: "la ciencia no es neutral, como muchos hombres de ciencia intentan convencerse a sí mismos" (1977, p. 155), nunca más permanecer como ratones callados, termina diciendo este cibernético, resignados a su ración de queso.

Pero la ratonera está repleta de queso llamado prosperidad creciente, consumo masivo, y la fuerza destructora comprimida en el muelle de la ratonera es el poder económico, acuyos intereses sirve la tecnocracia. Y de repente ... izas!, nuestra libertad se pierde. (Beer, 1977, p. 155)

Esta dura reflexión de Beer en que nos advierte que estamos perdiendo la libertad, es un buen motivo para que reflexionen un poco los que son considerados líderes, lo que se asumen como tales o los que pretender formar nuevos líderes, pues corren el riesgo de contribuir, de manera inocente y bien intencionada, con la opresión que se genera por medio de la economía, por ello considero que todos los autonombrados o nombrados por otros, como líderes, voltear hacia la filosofía, para evitar ser cómplices de la opresión. A su vez, la comunidad filosófica debería mirar y apoyar a formar líderes críticos, allende sus actuales modelos de enseñanza. Se necesita una alianza entre ambos, en México, si queremos un nuevo país, allende lo dicho por el entrante presidente del país.

Por ello advierte Beer (1971) del solipsismo, que incluye los problemas psicológicos ya que sus decisiones directivas pueden proyectar las dificultades de su propia personalidad, pero también las decisiones de la empresa suelen ser el resultado de una lucha y conflicto entre sus directivos. Pide se forme una nueva clase de directivos que puedan mandar a los hombres, pero también y encarar científicamente los problemas, apoyado en una formación filosófica fuerte ya que le ayudará como un modelo para esclarecer sus razones y soluciones, para evitar caer en el solipsismo 
o idea subjetiva, ya que "no conoce cosas; conoce sus percepciones de las cosas" (p. 553). Así, la percepción de las cosas, la existencia de las cosas percibidas es inferida y por lo mismo puede ser errónea, sostiene Beer que por dicho motivo no hay una escuela seria de solipsismo en filosofía. Considera que una mala administración -y un liderazgo- supone que todo es una proyección de su propia mente, cayendo en el error de que todo lo que él conoce coincide con el modelo que su propia mente tiene del mundo, tal como supone que es. En contra parte, el científico sabe, en Beer, que el mundo real no coincide con su modelo de mundo. "Pero el mal director es el que actúa como si creyera que su modelo conceptual del mundo abarca verdaderamente el mundo real” (1971, p. 554).

Lo anterior aplíquese para los supuestos líderes, que más que ayudar con su liderazgo contribuyen a enviar a la gente a la ratonera -como vimos con Beer-, desde sus buenas intenciones. Por lo que advierte del peligro de que dichos solipsistas se una en un grupo, pues todos estarán convencidos de su propia verdad, por lo que se opondrán contra cualquier otra postura, del mismo modo, al consultarse entre sí convergerán en una misa idea, ideal; lo cual es muy peligroso si están en puestos claves de la empresa, política u otra institución desde la cual se pueda perjudicar a miles de personas, así: "El partido de linchadores es uno de esos grupos que mantienen opiniones solipsistas, que, sin embargo, ha desembocado en una acción horripilante" (Beer, 1971. P. 555). Por ello deberán buscar la colaboración de filósofos y científicos -no solipsistas a la vez-, así el director, el líder elegirá aceptar o rechazar sus consejos. "El hombre práctico necesitará emprender una acción práctica. El científico está dispuesto a ayudarle" (Beer, 1971, p. 557).

Este es un buen pretexto para referir al filósofo novohispano, Carlos de Sigüenza y Góngora (1984), que refería que no se debería de debatir sobre el origen de la producción de las mejores ideas, pues para unos estaba en el pasado y para otros en las modernas. Él en contraparte propone la noción de innovación para destacar lo útil y provechoso, por ello no importa si la idea es antigua o moderna, sino que sea provechosa para nosotros. Por ello, después de haber expuesto el actual panorama mexicano con ejemplos de los llamados liderazgos de los que dicen que actualmente nos 
influyen -los foráneos los dejaremos para otro momento-, se nos hace creer qué porque algunas universidades privadas dicen que en sus aulas se forman líderes, esos centros poseen la fórmula mágica de la misma. En cambio, desde una universidad pública y desde la filosofía, intento presentar una muestra de innovación, útil y provechosa, desde los recuerdos del futuro -que usualmente Ilaman pasado- por medio del diálogo entre Sócrates y Critobulo, como pretexto para hablar de varios temas, el primero aborda el arte de la administración -como ya expusimos más arriba como filosofía aplicada a decir de Beer-, con el pretexto de administrar una hacienda, para terminar resaltando una idea del mundo clásico sobre liderazgo.

Aquí se da la primera gran enseñanza: "es propio de un buen administrador saber utilizar también a los enemigos para obtener provecho de ellos". (Jenofonte, 2015, p. 218) Para ello no sólo hay que administrar riquezas sino también personas, que es lo más fundamental de esta arte, por ejemplo, menciona Critobulo que hay diestros en la guerra y otros son diestros en la paz, y ambos no están dispuestos a practicar lo contrario; otros gustan de dados y malas compañías; otros se aplican con ahínco al trabajo y procuran ingresos. Así que difícilmente se puede hacer algo con eses tipo de subordinados para Isómaco, pero si los dueños de esos esclavos son duros con ellos, y a la vez, esos señores gustan de la gula, la lujuria, la embriaguez o "ambiciones estúpidas y costosas" (Jenofonte, 2015, p. 220) no logrará, sino que le obedezcan, por miedo a la tortura y castigo severo. Pero si se comporta como líder, el administrador, deberá tener dominio de sus propias pasiones, por ello es muy importante enseñar a los hombres a que aprenda a "administrar su hacienda" -su propia riqueza-, que es una manera de conocerse a sí mismo. Esto último sigue pasando desapercibido para el filósofo promedio en México, así como en los mismos llamados humanistas. Falta mucho por cambiar y por reaprender desde el mundo de la empresa como de las mismas humanidades, urge se reencuentren los más pronto posible para beneficio de millones de mexicanos excluidos -esperamos sirva a ello este texto-.

Esto lo pudimos confirmar por medio de una nota que apareció en el periódico, del 18 de mayo de este año, en El financiero, por medio de opinión de Gustavo Armenta (2018, p. 6), ahí 
menciona que dentro del "Foro Vidanta" -en Nuevo Vallarta, Nayarit- donde estuvieron presentes estudiantes de turismo, resalta el pronunciamiento que hizo Daniel Chávez Morán, (CEO) de Vidanta expuso varias ideas a ejecutar, muy interesantes, la que nos compete aquí es que mencionó que él quiere que sus trabajadores tengan una vida digna y que para ello les subirá el sueldo -pero a su vez, deberá recortar algunos empleados- en tres etapas, el que pasa cada una de ellas recibirá un aumento del 15\%, así que deberán pasar por un programa de capacitación; otro curso será para que se capaciten en un puesto mayor al que actualmente desempeñan, que como recompensa les generará otro aumento del 15\%; y finalmente, el que tiene que ver con lo dicho por Iscómaco, el tomar dos cursos de finanzas personales "para que puedan usar más eficientemente el dinero que ganan". (Chávez en Armenta, 2018, p. 6) Aquí Armenta cita textualmente lo dicho por Daniel Chávez, "para que todos tengan un nivel de vida digna" (Chávez en Armenta, 2018, p. 6), en que incluye a 17 mil trabajadores que con dichas capacitaciones obtendrán al final, un aumento del $45 \%$ de su sueldo más el aumento anual, llegará a 50\%, también les prestará sin cobrar interés, por la mitad de lo que necesiten. Clama Daniel Chávez, a sus colegas de la rama del turismo, pero nosotros ampliamos más su voz a todos los sectores productivos del país:

Invito a mis compañeros a que le echen ganas, porque sueño y soñamos todos los que trabajamos en esta empresa, en que podamos decir que somos la primera organización mexicana en la que todos los que participamos en ella tenemos un salario que nos permite tener un nivel de vida digna" (Chávez, en Armenta, 2018, p. 6)

Como vemos, si hay buena voluntad se puede porque se puede. Así, podremos colocar a uno de ellos, regresando a Isómaco, para que administre la riqueza de un hacendado que ponen bajo su responsabilidad, a de llamársele colaborador -ahora se le dice directo, ejecutivo o CEO-, no sirviente o esclavo. Previamente hay que identificar qué tipos de inclinaciones tiene -lo que hace actualmente el área de recursos humanos o empresas contratadas para cumplir con esa responsabilidad- a fin de evitar un desorden en la administración -entre ellas la falta de liderazgo ante los colaboradores de su organización, empresa, etc.-- 
Critobulo e Iscómaco (Jenofonte, 2015) concuerdan en que antes de tener un administradorcolaborador en la hacienda es muy importante enseñar a la esposa este mismo arte, ya que el hombre el que genera la riqueza y que en la mayoría de los casos quien la gasta es la mujer. Así que, si a ella se le educa en la administración, si lo hace bien, aumentará la hacienda; si lo hace mal, arruinará la hacienda. De la ahí la importancia de que cada matrimonio deberá de ser igualitario entre el hombre y la mujer ya que en el matrimonio ambos tienen necesidad de "dar y recibir equitativamente" de modo que ambos deberán ejercer la facultad de autocontrol y en la libertad ambos- de manera que el mejor guíe al otro. Es decir, si ella es mejor administradora y generadora de riqueza, el varón deberá encargarse de administrar correctamente el fruto de dicha abundancia no despilfarro-, aún en el supuesto mundo griego -que dicen era machista-, este tipo de mujer era muy admirada, al grado que se les podía proponer para administra el Estado, ser gobernadora de todo su pueblo.

Si la mujer es más eficiente, el varón deberá de cambiar de labores -excepto tejer por ser una labor exclusiva femenina-, entonces deberá ser el responsable de vigilar los víveres y encargarse de los esclavos, y dentro de ellos hacer de algunos capaces, leales y eficientes, y recompensarlas por su labor, y castigar severamente cualquier acto contario. Es decir, lo anterior era responsabilidad de la mujer que tenía un marido con riqueza, y que actualmente sigue sin ser reconocida esta labor femenina en el mundo griego. Aquí viene la segunda gran enseñanza: nada hay más útil, ni tan hermoso para los hombres que el orden.

El orden se deberá manifestar en cada acción de la vida, de tal modo que, si en la guerra alguien da una orden confusa a su ejército, será presa fácil del enemigo, y será además un amargo espectáculo para los amigos al ver como son vencidos o sometidos. Se estorban los unos a los otros, como ocurre en la guerra, en contraparte: "un ejército en orden es el espectáculo más bello para los amigos y el más desagradable para los enemigos". (Jenofonte, 2015, p. 248) Cuando marchan en orden, aunque sean decenas de millares, se mueven como un solo hombre. También refiere Iscómaco que, en los bracos de guerra, llenos de soldados, son admirados por sus amigos y temidos 
por los enemigos por su rapidez; embarcan y desembarcan en orden, por lo tanto: "si quieres liberarte de esta confusión y saber administrar correctamente los bienes, poder coger fácilmente lo que necesites y poder usarlo". (Jenofonte, 2015, p. 249)

Menciona que subió a un barco mercante fenicio y que lo encontró tan perfectamente ordenado. Menciona que navegan con muchos artefactos colgantes, transportan numerosas armas para sus tripulantes, además va repleta de mercancías en un espacio mayor de una habitación mediana de diez camas, todo colocado de tal manera que no se estorban unas con otras. Además, el oficial de proa o auxiliar del timonel, conoce al dedillo el lugar de cada cosa que incluso fuera del barco sabe qué hace falta. Recuerda Iscómaco que dicho oficial revisaba en sus ratos libres todo lo que se iba a necesitar para el viaje. Por ello considera que las amenazas y castigos de los dioses, espera los descuidados, el hombre prevenido no es afectado por la divinidad, por lo que, del mismo modo, se ha de proceder en la administración de la hacienda, hay que poner en orden todo, de tal manera, que sabe qué hace falta sin buscar de manera desesperada. Todos ganan en belleza si está todo en orden.

Así llegamos a la tercera gran enseñanza: si el maestro o amo enseña mal, enseña a ser indolente, es difícil que el criado resulte diligente. Por ende, para Iscómaco no hay esclavos buenos ni manos de un amo malo; sólo al ojo del amo se consiguen los mejores resultados. Aquí llegamos al punto más importante de la administración y que se vincularemos al ideal de empresas e instituciones mexicanas que hablan de liderazgo y formación de líderes. Para este griego se "debe de aprender a mandar a los trabajadores" (Jenofonte, 2015, p. 267). Hay que formar personas: con dotes de mando, de ser amos. Menciona que había dos modos de proceder: 1. Dando un castigo al que intenta desobedecer; y 2. Premiar con buen trato al que atiende las indicaciones. Pero si quieres que los hombres sean más obedientes debes de tener medios de ayudarles -como vimos con Daniel Chávez-, de que obren de acuerdo con los intereses del líder. Sobre todo, obrar de manera justa con ellos, ser amables y tratarlos "como a personas libres". (Jenofonte, 2015, p. 271) 
Pero no basta, ya que todo líder debe aprender cómo a realizar cada trabajo en que pretender ser obedecido, no deberá de ignorar que hay qué hay que hacer y cómo debe de hacerse. Así que, si quiere ser capaz y diligente, de mando justo, deberán aprender a dedicarse con éxito a la agricultura, que, a su vez, la enseñará: qué debe hacer, cómo y cuándo. No basta decir que se dedica a la agricultura hay que saber practicarla. Pero no como los artesanos y otros profesionistas que ocultan sus artes, sino como agricultores: "Preguntes lo que preguntes sobre sus trabajos bien hechos, no te ocultarán nada acerca de cómo le hicieron". (Jenofonte, 2015, p.273) Por qué: "la agricultura parece que hace más nobles de corazón a los que se dedican a ella". (Jenofonte 2015, p. 273) Un buen labrador, mirando cualquier zona del campo, sabe que sembrar y que plantar, incluso en terreno extraño, observando el territorio; del arte de la agricultura se obtienen consejos y secretos a decir de Iscómaco: "la agricultura es un arte tan humano y tan afable que no tienes más que oír y escuchar para convertirte al punto en experto". (Jenofonte, 2015, p. 285)

Ahora el gran secreto en que se resume todo el presente escrito: "la tierra no exhibe nada para engañar, sino que revela simplemente y con veracidad lo que puede y lo que no puede producir". (Jenofonte, 2015, p.285) Con este método se puede generar dinero, ahora has aprendido, enséñalo a los demás, le pide a Sócrates. Desde ahora podemos ser unos apasionados de la agricultura. Por lo tanto, no importa en que universidad se estudie, grado o especialidad se tenga, puede ser un buen administrador o líder, basta con ser un buen agricultor; y no ser solipsista. Sócrates exclama sobre este asunto: "y declaro bajo juramento que te creo: todos los hombres aman por naturaleza las cosas que piensan que van a sacar provecho". (Jenofonte, 2015, p. 292)

Concuerdan Iscómaco y Sócrates, en la cuarta gran enseñanza: en que hay aspectos comunes a todas las actividades -ciencias- como es la agricultura, la política, la administración y otras -como la filosofía-, en el don de mando. Cada cual ama lo que se le saca de provecho, por ello, obedecen y trabajan con disciplina y si trabaja a la par jefe y subordinados, se conseguirán los objetivos: "El jefe ante quien sus subordinados muestran esta disposición de espíritu resulta un dirigente formidable, y no los que destacan sobre sus soldados por su fuerza corporal". (Jenofonte, 
2015, p. 292) No basta ser el mejor en su trabajo o especialidad si no es capaz de inculcar en sus subordinados el sentimiento de que tienen que seguirle a pesar de todo tipo de peligro. Para Jenofonte estos hombres, se pueden llamar jefes, "grandes de espíritu", es: "un hombre grande el que puede realizar grandes acciones más con su voluntad que con su fuerza". (Jenofonte, 2015, p. 292) Así, si tiene la autoridad -que le otorgan sus subordinados- hace de sus subordinados hombres diligentes, entusiastas y constantes en el trabajo, lleva a todos al éxito. Este líder, con cuya presencia: "estimula a los obreros a infunde coraje a todos, emulación mutua y ambición de ser cada uno mejor". (Jenofonte, 2015, p. 292)

Finalmente, la quinta gran enseñanza de Jenofonte falta otro tipo de educación para ser un buen líder, deberá apoyarse fundamentalmente: en la filosofía. Ya que. "la facultad de mandar a los hombres que obedezcan de buen grado surge con claridad en los verdaderamente iniciados en la sabiduría". (Jenofonte, 2015, p. 293) Amable lector a Usted le toca decidir si innovaba en su vida desde la filosofía, en su afán de perfeccionarse en el arte de la administración y liderazgo o seguir pagando mucho dinero por asistir a eternas capacitaciones que le harán perder su tiempo y dinero. Le diría que asista a las escuelas de filosofía del país, pero ahí les da miedo o ignoran este secreto, por ende, no porque sea egresado de filosofía sabrá tratar de esos asuntos, también a ellos los debemos reeducar en pensar la filosofía más allá de los simples muros de las aulas universitarias. Mejor vuelva o inicie su transformación desde la misma agricultura, y si no pude salir de la ciudad, al menos en el arte menor, pero sabio, de la jardinería. Si bien, hay muy pocos, que penetramos en estos secretos por lo general no se nos busca ni se nos consulta para orientar. Falta que las organizaciones y empresas, en general, se abran a nuevas vías y manera de capacitarse en el arte de la administración, que, dicho sea de paso, es una disciplina filosófica, y que urge retomar en las mismas escuelas de filosofía, en el territorio mexicano. Usted decide, amable lector formarse como líder con formación filosófica o sólo ser líder. 


\section{Referencias:}

100 líderes más influyentes del sector energético en México. (Noviembre-diciembre, 2006) Petróleo \& energía. México. Año 13. T. 103. N. 01. Pp. 14-50

13 promesas de la ingeniería. (Abril, 2018) Manufactura. México. N. 267. Pp. 14-50

Abbagnano, N. (1962) Introducción al existencialismo. Traducción José Gaos. México. 2a edición. Breviarios del FCE N 108. FCE.

Aranguren, F.; Amescua, A.; Basagoiti, J.M. (1974) Pensamiento empresarial mexicano. Monterrey. Avance editorial.

Armenta, G. (18 de mayo de 2018) Ofrece Daniel Chávez aumentar 50\% los salarios de sus $17 \mathrm{mil}$ empleados. El Financiero. A. XXXVII. N. 10098.

Beer, S. (1971) Decisión y control. El significado de la investigación de operaciones y la administración cibernética. Traducción Manuel Suárez. México. FCE

Beer, S. (1977) Diseñando la libertad. Traducción Amparo Rodríguez. México. FCE.

Cicerón. (2016) Obras filosóficas I. Sobre la naturaleza de los dioses. Introducción, traducción y notas de Víctor-José Herrero Llorente y Ángel Escobar. Madrid, España. Biblioteca Gredos.

Ibargüengoitia, A. (1995) Apuntes para una filosofía de la empresa. México. Cuaderno de filosofía No. 27. Universidad Iberoamericana, departamento de filosofía.

Jenofonte. (2015) Económico, en Diálogos. Introducción, traducción y notas Zaragoza. Madrid. Biblioteca Gredos. RBA

Los 300 líderes más influyentes de México. (Julio 2017) Líderes de México. Año 26, N. 137. Pp. 130276

ADN Político. El inconformismo activo. (15 de abril, 2018) Expansión. A- XLIX. N. 1332. Pp. 22-23

Lucena, P. (15 de abril,2018) Contra el déficit de talento. La EGADE tiene un sueño y su decano, Ignacio de la Vega, quiere poner las bases para lograrlo. En Expansión. A. XLIX. N. 1332. 15 de abril. Pp. 60-62

Moreno, L y, De la Rosa, E. (23 de septiembre de 2018) México se juega 650 mil mdd en la renovación de acuerdos. Milenio Jalisco. A. 21. N. 7653.

Ruiz, C. (18 de mayo de 2018) Liderazgo dinámico. El Financiero. A. XXXVII. N. 10098.

Sigüenza, C. (1984) Teatro de virtudes políticas. En Seis obras. Prólogo Irving A. Leonard. Notas y cronología William G. Bryant. Venezuela. Biblioteca Ayacucho. 